\title{
I-URBAN REVITALIZATION: CONCEPTUAL MODELING, IMPLEMENTATION, AND VISUALIZATION TOWARDS SUSTAINABLE URBAN PLANNING USING CITYGML
}

\author{
K. Akahoshi ${ }^{1, *}$, N. Ishimaru ${ }^{2}$, C. Kurokawa ${ }^{3}$, Y. Tanaka ${ }^{4}$, T. Oishi ${ }^{5}$, T. Kutzner ${ }^{6}$, T. H. Kolbe ${ }^{6}$ \\ ${ }^{1}$ Cabinet Office Japan, 2-1-3, Kasumigaseki, Chiyoda-ku, Tokyo, Japan - k.akahoshi@kashika.or.jp \\ ${ }^{2}$ Hitachi, Ltd., 292 Yoshida-cho, Totsuka-ku, Yokohama, Kanagawa, Japan - nobuhiro.ishimaru.yu@hitachi.com \\ ${ }^{3}$ Asia Air Survey Co.,Ltd., 1-2-2 Manpukuji, Asao-ku, Kawasaki, Kanagawa, Japan - ckk.kurokawa@ajiko.co.jp \\ ${ }^{4}$ Urban Structure Visualization Promotion Organization, 5-10 Suzaki-machi Hakata-ku, Fukuoka, Japan - y.tanaka@kashika.or.jp \\ ${ }^{5}$ Panasonic Corporation, 1-5-1 Higashi-shinbashi, Minato-ku, Tokyo, Japan - oishi.tomohisa@jp.panasonic.com \\ ${ }^{6}$ Chair of Geoinformatics, Technical University of Munich, 80333 Munich, Germany - (kutzner, thomas.kolbe)@tum.de
}

\section{Commission IV, WG IV/10}

KEY WORDS: Urban Planning, CityGML, LOD (Levels of Detail), Statistical grid, AR (Augmented Reality)

\begin{abstract}
:
Japan is currently facing serious issues associated with an aging society and negative population growth. Urban structures, remnants of economic prosperity, are now hindrances to sustainable urban development, driving municipalities to seek efficient methods to manage this growth. Japanese municipalities continuously conduct surveys to collect data for urban planning purposes. However, lack of standardization and poor visualization tools prevent coordination and consensus-building among stakeholders during the planning process. The "i-Urban Revitalization" (i-UR) is an information infrastructure promoted by the Japanese government expected to enable municipalities to analyze and visualize their goals related to that process.

This paper presents the implementation of $\mathrm{i}$-UR. One approach employed for data standardization is to develop a CityGML Application Domain Extension (ADE) for urban planning that covers detailed attributes of city objects and mechanisms for global representation and analysis necessary for urban planning. The effectiveness of this ADE is being evaluated through data implementation and visualization experiments conducted in three municipalities in Japan. A prototype for the proposed "AR Consensus-formation system" is being developed for further utilization of the ADE. In addition, Ideathon events are being held to develop human resources in municipalities to promote urban revitalization and facilitate i-UR use. The ADE and i-UR tools described in this paper are expected to evolve based on feedback from users and experimental results.
\end{abstract}

\section{INTRODUCTION}

Urban planning has been contributing to the formation of healthy urban environments preventing disorganized urban sprawl and encouraging infrastructure development. In Japan, which is facing an aging society and negative population growth, urban areas are at a big turning point. New social issues such as a rapid increase of empty apartments and lands, and nonuniversal design of facilities depend heavily on sustainable development, especially in regional areas. This urban shrinkage is not only a problem in Japan, but is faced by many cities and regions in Europe and North America (Oswalt, 2005). Efficient urban management is required to address these issues, and municipalities recognize the significance and importance of the compact urban development from the perspective of administrative costs.

The "i-Urban Revitalization" (i-UR) is an information infrastructure that visualizes urban development plans and impacts using 3D maps (Cabinet Decision, 2018). The main goal of the i-UR is to present the situation in a particular region to people who are not familiar with this technology. Another goal is to encourage consensus-building among relevant stakeholders such as investors, citizens, and developers. The iUR evolves from "Mieruka (visualization; identifying problems and bringing them to the foreground)" on a 3D map using visualization technologies (Akahoshi et al., 2010).
The i-UR is built upon a collection of tools, data, and standards as shown in Figure 1. In order to realize the potential of i-UR using various municipal data, a sufficiently flexible and powerful 3D map standard is required. The Open Geospatial Consortium (OGC) standard CityGML is a widely utilized open data model and XML-based format for the storage and exchange of virtual 3D city models (Gröger et al., 2012). One of the key features of CityGML is the "Application Domain Extension" (ADE), a built-in mechanism of CityGML used to define application-specific extensions by adding new classes and properties (Biljecki et al., 2018).

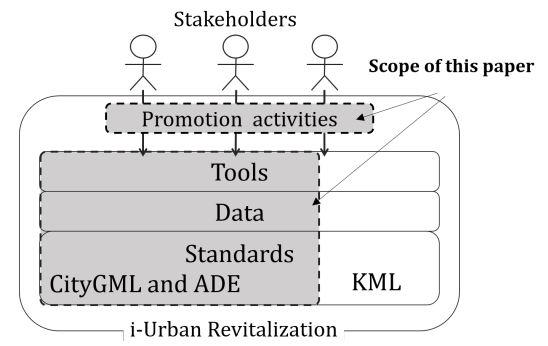

Figure 1. The structure of i-Urban Revitalization

This paper presents the conceptual modeling, the CityGML ADE encoding specification for urban planning (hereinafter referred to as the "Urban Planning ADE"), the data implementation, visualization experiments using Augmented

* Corresponding author 
Reality (AR) technologies, as well as promotion activities for iUR in Japanese municipalities. The aim is to assist in building consensus and to improve the quality and strategy of investment in urban revitalization as well as to lay foundations for technological innovation.

\section{RELATED WORK}

\subsection{Data Development by the Basic Survey of City Planning}

"The Basic Survey of City Planning" is being conducted regularly in accordance with the City Planning Act enacted in 1968 in Japan. Over 1,400 municipalities maintain 2D maps and statistics every five years. However, since the data format was left to the discretion of the municipalities, no standard has been established and it is unlikely that the outputs can be easily reproduced.

In addition, developing and maintaining 3D map data for large area applications such as urban planning tends to be costly and time consuming; therefore a more efficient method to secure 3D data is required such as utilizing the existing survey data.

The demand for reusable data that can be easily analyzed and clearly visualized has been increasing. Therefore, a standardized $3 \mathrm{D}$ data format compliant with international open standards is crucial to utilize and adopt the survey for i-UR across all municipalities.

\section{2 i-Urban Revitalization using OGC KML}

The government of Japan released "the Basic Policy of Urban Structure" in 2007 (Social Capital Development Council, 2007). The policy urges municipalities to consider transitioning to compact urban structures (Figure 2), and recognizes that providing a visual representation of information aids in consensus-building among stakeholders and encourages citizen participation in urban planning.

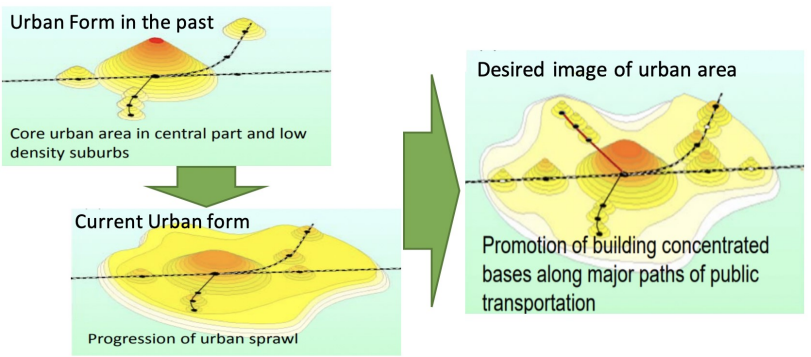

Figure 2. Formulating an urban plan for compact cities

The OGC standard KML (Burggraf, 2015) is being utilized to visualize statistical grid data and urban structures to facilitate decision making (Fukuoka Prefecture et al., 2019), satisfying the requirement to share knowledge and provide a support system (Akahoshi et al., 2018). A Cross Visualization that integrates information from various sources as well as a Time Series Visualization of urban growth from past to present are essential. Subsection 2.2.1 and 2.2.2 describe those methods, respectively.

However, further integration of 3D building geometry data and statistical grid data is required to establish more unified visualization and facilitate comprehensive analysis. Additionally, there is a requirement to use semantic information that could not be easily supported with OGC KML.
2.2.1 Cross Visualization: Cross Visualization in 3D yields two types of information - height and color - represented together on the map. Figure 3 shows an example of cross visualization. The height represents population, and the color represents transportation accessibility. This example shows populations in areas where transportation is easily accessible. Cross visualization is an effective method used to understand a city's current problems and strengths.

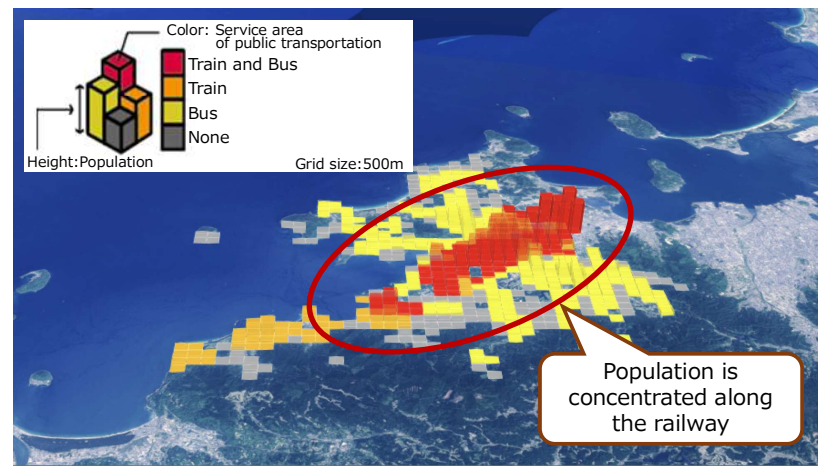

Figure 3. Cross Visualization of population and transportation accessibility

2.2.2 Time Series Visualization: In order to project into the future, it is important to assess changes over time. For example, changes over time of population, industrial structure, and infrastructure represent how a community has evolved over the years. Figure 4 shows an example of Time Series Visualization using population data from 50 years ago to the present and projects this into the future. Visualizing the spatial distribution and its change in population density makes it easier to understand the urban activities and study the structure of the city.

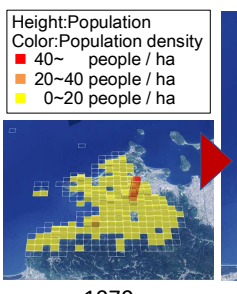

1970

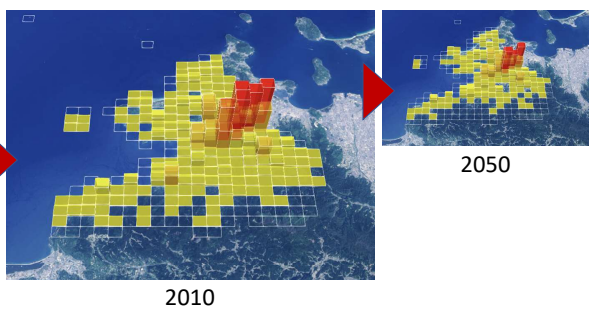

2010
Figure 4. Time Series Visualization of the changes in population density

\subsection{CityGML and ADE}

The OGC standard CityGML is an open data model and XMLbased format for virtual 3D city models and is widely used in the field of urban modeling (Gröger et al., 2012). It describes geometry data as well as semantic information in five standardized Levels of Detail (LOD) which can be useful as an information infrastructure and for information sharing. Various examples have shown the effectiveness of using CityGML such as the Helsinki $3 D+$ and its Digital Twins applications (Airaksinen et al., 2019) for city-wide data, and the Virtual Singapore (Soon, Khoo, 2017) for nation-wide data.

CityGML does not provide application-specific classes and properties, but does have a formalized mechanism to define such extensions called Application Domain Extension (ADE). According to a literature review by Biljecki et al. (2018), 44 ADEs currently exist that support not only different applications, 
such as the Utility Network $A D E$ for representing multi-utility networks (Kutzner et al., 2018) and the Energy $A D E$ for urban energy modelling (Nouvel et al., 2015), but also applicationindependent tasks, such as the IMGeo $A D E$ that harmonizes CityGML with the Dutch National Spatial Data Infrastructure (Van den Brink et al., 2013). However, the literature review also shows that no ADEs exist to date that support sustainable urban development as intended by the municipalities in Japan. An ADE for urban planning enables related information to be normalized and facilitate comparison of time periods and cities.

\subsection{Visualization Tools for Consensus-Building}

Various visualization tools have been developed to promote consensus-building such as physical city models (dioramas) and VR applications. However, these methods do not sufficiently address certain issues. For example, it is difficult to perform flexible volume studies using the physical model to change the size of a building or display and superimpose statistical information. VR technology has proven to be useful in areas such as smart cities as an analysis and decision-making tool. However, the cost limits access to this technology (Jamei et al., 2017). Nevertheless, in order to increase citizen participation in urban planning, the existing GIS (Geographic Information System) or VR tools should be used and adjusted as technology evolves. It is important to develop visualization tools that integrate available data using advanced technologies that account for i-UR and its underlying CityGML feature semantics.

In this regard, Augmented Reality (AR) technology, which has elements that can further enhance and expand VR technology, might be effective. An example verified AR mobile applications for smart cities within a university campus (Ramos et al., 2018) and opened the potential for applying AR technology to large urban areas.

\section{DEVELOPMENT OF THE URBAN PLANNING ADE}

Related works reveal that the lack of a standardized data model and format prevents the effective use of data for urban planning. In this chapter, we describe an open and standardized data model and format developed for i-UR as a CityGML ADE.

\subsection{Methodology}

The items of the Basic Survey of City Planning in Japan (Regulation for Enforcement of the City Planning Act, 2018) are reassembled to create the i-UR data model. As mentioned in Section 2.1, each prefecture in Japan conducts a survey every five years in accordance with laws and regulations. This ensures the quality, comprehensiveness, and continuity of the data. The survey includes basic information necessary for i-UR and this information is adapted for the modeling process.

The i-UR data model was developed to harmonize with CityGML by conforming to the CityGML ADE extension mechanism. In particular, the items of the Basic Survey of City Planning which are already defined in CityGML are reused, and others which are not defined in CityGML are modeled according to the rules for the CityGML ADE.

\subsection{Conceptual Modeling}

First, all items in the Basic Survey of City Planning shown on the left side in Table 1 are divided into two components: a) items defined in CityGML as objects or properties, and b) items not defined in CityGML. Then, the items in b) are classified into four subcomponents according to their characteristics:
b-1) Detailed information of a CityGML object
(e.g. total floor area and owner of a building)
b-2) Constraints and conditions
(e.g. administrative boundary and zoning)
b-3) Grid with values
(e.g. population distribution within a grid)
b-4) Global model
(e.g. population distribution on national or worldwide scale)

In city planning, characteristics of features such as buildings are aggregated into statistical units for global representation and analysis. An administrative boundary is often used as a statistical unit. However, the statistical data tabulated by administrative boundaries is insufficient in designing administrative plans such as social infrastructure improvement when the sizes of municipalities are different and when they change their boundary based on municipal mergers and dissolutions. To facilitate time-series comparison and regional comparison, grid statistics which divides the whole area into small grids is widely used in Japan. The size of the grids is standardized in Japan (Statistics Bureau of Japan, 1996) same as in EU, and grid statistics has been applied to municipal operations to allow using historical statistics data accumulated over 50 years. In addition, although statistical analysis with grids is often applied on a national or worldwide level, the LODs defined in CityGML do not cover such a rough description. Therefore, new concepts, i.e. a grid with values (b3 ) and a global model (b-4), are introduced to define the i-UR data model.

Thereby, a set of five components is proposed as a concept of the i-UR data model, and finally, the items in the survey are decomposed into the five components shown in Table 1.

\begin{tabular}{|c|c|c|c|c|c|c|}
\hline \multirow{2}{*}{ No. } & \multirow{2}{*}{ Major items } & \multicolumn{5}{|c|}{ Components } \\
\hline & & a & b-1 & b-2 & b-3 & b-4 \\
\hline 1 & Spatial distribution of land prices & & & & $\mathrm{x}$ & $\mathrm{x}$ \\
\hline 2 & $\begin{array}{l}\text { Number of offices and employees, value of } \\
\text { manufacturers' shipments, value of commercial sales }\end{array}$ & & & & $\mathrm{x}$ & $\mathrm{x}$ \\
\hline 3 & $\begin{array}{l}\text { Number of households and housing units, housing scale } \\
\text { and other housing conditions }\end{array}$ & & & & $\mathrm{x}$ & $\mathrm{x}$ \\
\hline 4 & Usage, structure, area, and total floor area of the building & $\mathrm{x}$ & $\mathrm{x}$ & & & \\
\hline 5 & Location of city facilities, status of use and maintenance & & & $\mathrm{x}$ & & \\
\hline 6 & $\begin{array}{l}\text { Location, zone, area and status of use of national land } \\
\text { and public land }\end{array}$ & $\mathrm{x}$ & $\mathrm{x}$ & & & \\
\hline 7 & Land's natural environment & $\mathrm{x}$ & $\mathrm{x}$ & & & \\
\hline 8 & Housing developments and building dynamics & & $\mathrm{x}$ & & $\mathrm{x}$ & $\mathrm{x}$ \\
\hline 9 & Occurrences of pollution and disasters & & & $\mathrm{x}$ & & \\
\hline 10 & Execution situation of city planning related projects & & & $\mathrm{x}$ & & \\
\hline 11 & Location of the Recreation Facility and Status of Use & & & $\mathrm{x}$ & & \\
\hline 12 & $\begin{array}{l}\text { Other necessary items for city planning according to local } \\
\text { features }\end{array}$ & & $\mathrm{x}$ & $\mathrm{x}$ & & \\
\hline
\end{tabular}

Table 1. Items in the Basic Survey of City Planning in Japan mapped to i-UR

\subsection{Urban Planning ADE}

Based on the results of conceptual modeling, each component is described as a thematic module in the i-UR data model. The first module includes CityGML objects and their properties and is imported from CityGML; the other modules define new objects within the "Urban Planning ADE".

3.3.1 Urban Object Module: The Urban Object Module defines additional properties of City Objects necessary for urban assessment and planning. Those already defined in CityGML 
are imported without changes. Figure 5 shows a part of this module, which extends bldg::_AbstractBuilding. The classes colored in gray are imported from CityGML or GML.

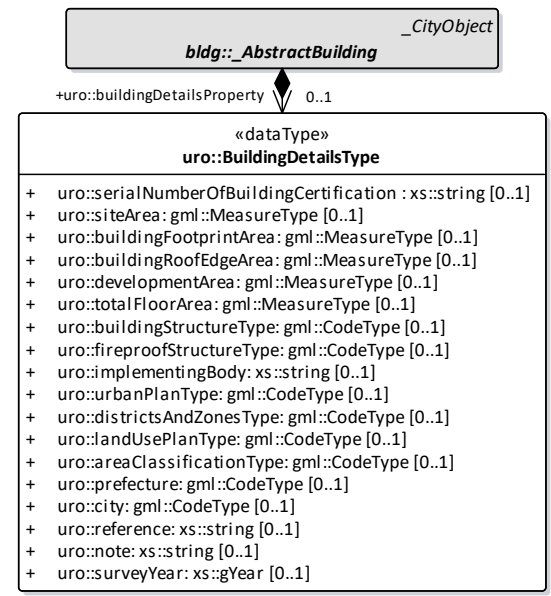

Figure 5. A part of the UML class diagram of the Urban Object Module

3.3.2 Urban Function Module: The Urban Function Module contains constraints and conditions for urban development, which are conceptual and virtual objects, such as administrative boundaries and zoning in urban areas. These objects (hereafter called "urban function objects") are not visible in the real world, but guide and lead city objects such as land use and buildings to their intended state. This type of feature is not defined in CityGML, so that these are extended from core::_CityObject, a root object in CityGML (Figure 6).

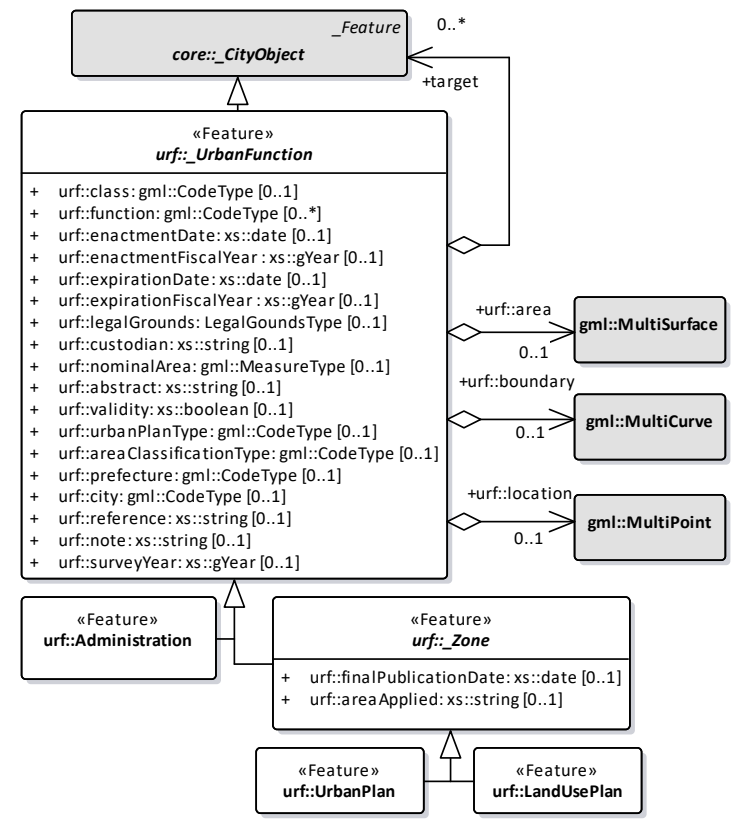

Figure 6. A part of the UML class diagram of the Urban Function Module

An urban function object can obtain its geometry directly or indirectly through associations. When it has an association with a city object, the city object is added enriched with a new function. For example, a substantial well-constructed public building (e.g. school) is designated as an evacuation shelter when a disaster occurs.
3.3.3 Statistical Grid Module: The Statistical Grid Module enables users to perform the time series analysis and regional comparison as described in section 2.2. A grid cell is a space separated in an algorithmic way with a nesting structure; each grid has an identifier to distinguish the grid location. This module assigns statistical values to each grid cell. As the location of the grid is fixed and the sizes of each grid are almost the same, it is easy to compare inter-grid characteristics.

A root class of this module is urg::_StatisticalGrid. Each statistical grid cell has its identifier and acts as a feature, and

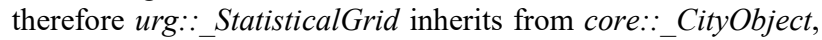
(Figure 7). The value of a grid cell can not only be statistical data such as population, but also data of administrative boundaries, roads, railroads, public facilities, land use etc.

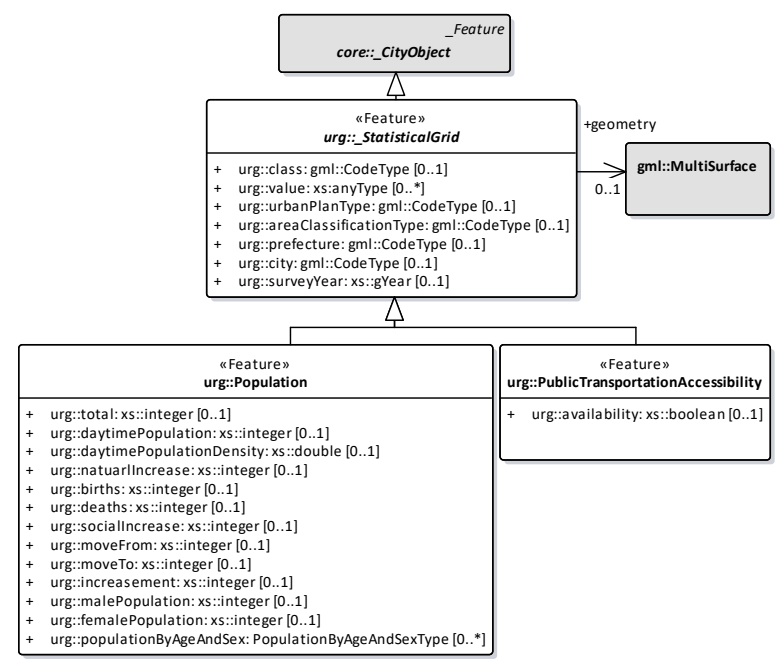

Figure 7. A part of the UML class diagram of the Statistical Grid Module

Each statistical grid cell obtains its spatial attribute directly or indirectly, which facilitates integration of geospatial information and statistics, and enables users to visualize quantitative statistical data on a map and analyze it using geospatial objects.

3.3.4 Extended LOD Module: The Extended LOD Module extends the CityGML LOD concept and defines two extra LODs for statistical grids, LOD-1 (minus one) for nationwide city models and LOD-2 (minus two) for worldwide city models. Since grid cells provide an overview of the real world, this module defines ure::lod-1MultiSurface and ure::lod2MultiSurface as shown in Figure 8 as associations of urg::_StatisticalGrid to declare explicitly that a grid described in LOD-1 or LOD-2 represents the global city model.

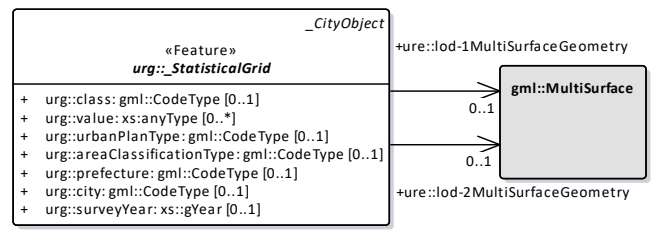

Figure 8. UML class diagram of the Extended LOD Module

These extended LODs enable users to employ global city models for comparison and analysis of cities and maintain consistency between LOD 0 to 4 . They also enable using 3D city models in policy making phases such as developing national and regional spatial plans (Figure 9). 

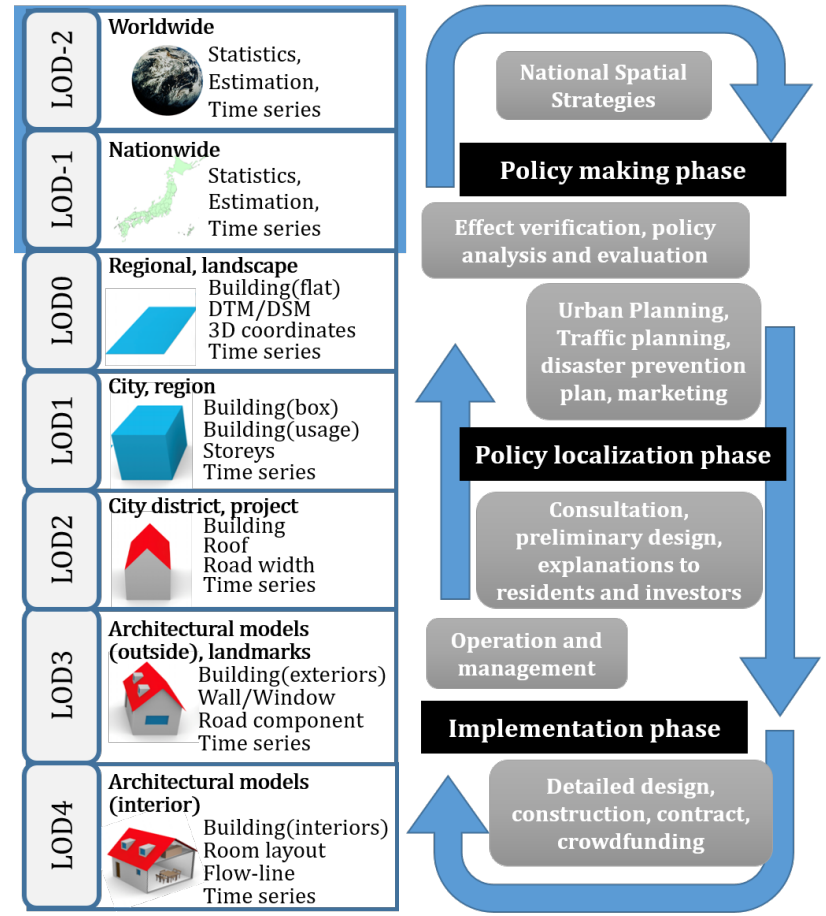

Figure 9. Concept of the Extended LOD (based on Biljecki et al., 2017 and Cabinet Office of Japan, 2019)

\subsection{Result of Urban Planning ADE Development}

The specification and XML Schema of the Urban Planning ADE described in this chapter were published as "i-UR 1.1" in November 2019 and can be freely accessed from (Cabinet Office of Japan, 2019). This ADE provides the standardized data model and encoding format for urban planning. Its semantics allow users not only to visualize cities, but also analyze and quantify urban challenges.

The Urban Planning ADE has been developed as an extension for CityGML 2.0. The importance and usefulness of some of the concepts introduced in the $\mathrm{ADE}$ is becoming clear when looking at the next major version of CityGML 3.0 to be published in 2020 (Kutzner et al., 2020), where similar concepts will be introduced such as the logical spaces. These spaces are equivalent to the virtual objects defined in the Urban Function Module of the ADE.

\section{DATA IMPLEMENTATION EXPERIMENTS}

This chapter describes data implementation and application demonstration experiments to validate the effectiveness of $\mathrm{i}-\mathrm{UR}$

\subsection{Overview of Case Study Areas}

The demonstration experiments were conducted in three citylevel municipalities shown in Table 2. The current situation and challenges in these case study areas are summarized as follows:

Munakata City: As a commuter town, the population grew rapidly between 1965 and 1980 due to the development of housing complexes. The total population has continued to increase moderately, however the population is increasing only in the city center and is decreasing in the suburbs. In addition, there are variations in the region regarding the degree of aging of the population and aging of buildings.
Chino City: One key urban development issue in Chino City is the presence of randomly distributed vacant lots and houses in urban areas. The city staff have tried to figure out how the city buildings are used. However, due to the fact that information such as the year of construction was created separately from the location map, it was difficult to understand the relationship between location and information.

Mutsu City: The urban areas in Mutsu City are becoming suburban, and it is expected that there will be an increase in unoccupied houses even in urban areas including residential and commercial districts. Redevelopment in urban areas and suburban development regulations are required to maximize effective use of existing public facilities and financial resources.

\begin{tabular}{lccc}
\hline $\begin{array}{c}\text { Name of } \\
\text { city }\end{array}$ & $\begin{array}{c}\text { Area } \\
\left(\mathbf{k m}^{\mathbf{2}} \mathbf{)}\right.\end{array}$ & $\begin{array}{c}\text { Population } \\
\left(\mathbf{1 0}^{\mathbf{3}} \mathbf{)}\right.\end{array}$ & Location \\
\hline Munakata & 119.92 & 97 & \\
Chino & 266.59 & 55.5 & \\
Mutsu & 864.16 & 56.8 & \begin{tabular}{c} 
Munakata \\
\hline
\end{tabular}
\end{tabular}

Table 2. Overview of the case study areas

\subsection{Results and Comparison with the Experiment}

The results of the Basic Survey of City Planning in each municipality were converted to i-UR data and each dataset was displayed on a 3D map using CesiumJS (Figure 10). The building data is color-coded according to properties such as usage, number of floors, and year of construction.

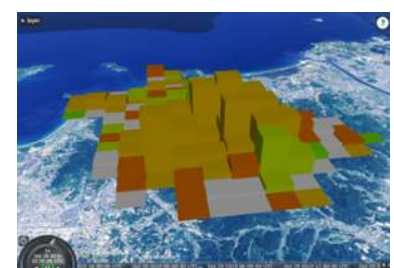

a. Munakata City

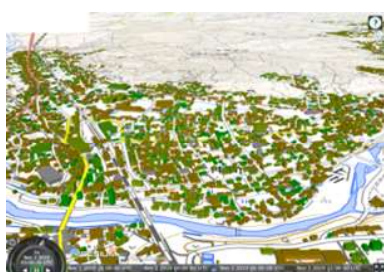
b. Chino City

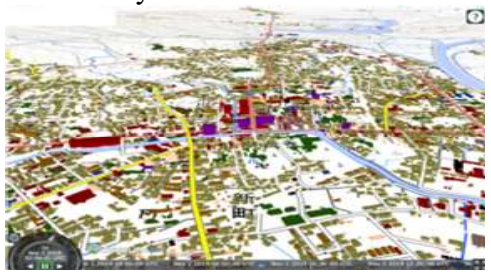

c. Mutsu City

Figure 10. i-UR data implementation in three municipalities

Figure 10-a shows the distribution of buildings. The number of buildings and the year of construction are aggregated into a grid, and pairs of values from the grid are used to create a 3D graph. The graph is then placed on the virtual globe to visualize the situation as statistical grid. While explaining the situation to the residents, it was possible to show the local situation in an easyto-understand manner by employing a data set provided by i-UR

Figure 10-b shows the 3D building data color-coded according to the year of construction, visualizing the distribution of buildings. The figure made it possible to intuitively understand the distribution of building usage for such items as houses and shops; and the distribution of buildings by construction year, such as identifying where old buildings are concentrated. 
Figure 10-c shows the color-coded 3D building data according to usage. The distribution of building usage such as public facilities and houses can be clearly observed. In addition to a data summary, the building situation can be shown in 3D and represented clearly to the residents.

Formerly in each case it was difficult to discern the actual situation and to explain it to the residents in an easy-tounderstand manner. However, by applying i-UR, the situation and problems of the city can be analyzed quantitatively and visualized intuitively, and can be easily demonstrated to the residents of each locality. Additionally, by using historical statistics data accumulated over 50 years, the LOD extended Statistical Grid data can be utilized for planning purposes even in areas without detailed building data.

\section{AR VISUALIZATION EXPERIMENTS: "AR CONSENSUS-FORMATION SYSTEM" FOR I-UR}

This chapter describes the results of i-UR application experiments through the development and implementation of the "AR Consensus-formation system".

\subsection{Consensus-Building with AR Technologies}

Urban development is often time consuming. Enormous time and effort are spent forming a consensus between many stakeholders. In order to increase transparency among them, visualization tools for consensus-building are required. In the development of i-UR, it is necessary to evaluate these tools and the possibility of additional technological development.

Related works reveal that AR might help to develop a visual understanding of buildings and contribute to a large-scale field such as urban planning or urban development, where there is a need for a large geospatial dataset. Therefore, we proposed a tool called "AR Consensus-formation system" for i-UR, and developed a prototype of the system after defining a comprehensive list of requirements.

\subsection{Development of the AR Prototype System}

First we defined the overall image and requirements of the suggested AR Consensus-formation system for i-UR as shown in Table 3, so that it can be effectively utilized for planning in actual urban sites in Japan.

\begin{tabular}{l|l}
\hline Concept & $\begin{array}{l}\text {-Multiple people can share the same geospatial data at the same } \\
\text { time. } \\
\text {-Controls or changes can be made by the operation of a conductor. } \\
\text {-Discussion and verification can be made in the same virtual } \\
\text { space. }\end{array}$ \\
\hline Devices used & $\begin{array}{l}\text { AR smart glass (for the required number of people), tablet (1 } \\
\text { unit). }\end{array}$ \\
\hline map scale & $1 / 10,000$ \\
\hline Required space & At least $3 \mathrm{~m} \times 3 \mathrm{~m}$ space, (a general meeting space) \\
\hline
\end{tabular}

Table 3. Concept and Requirements of the Prototype System

After accounting for the effective resolution of issues in urban planning, the functions that can be realized by this prototype were defined as follows:

- Reproducing the geospatial data sets of a city from CityGML and Urban Planning ADE.

- Controlling via tablet, investigating a massive quantity of geospatial data sets synchronized on AR glasses sharing the same geospatial data among a large group of people.
Each element of the functions shown above was programmed, and the content was integrated by combining these functions into one unique application. The prototype developed in this way has the following technical features:

1. Landscape simulation functions which are difficult to achieve with other tools such as physical city models.

2. Content sharing functions to activate communication among multiple people and promote consensus building.

3. The application corresponding to the work process for the stakeholders to solve the problem at the actual planning site.

Thereafter, a system was built to enable a large group of people to browse and experience the shared contents through AR smart glasses. In this study, Microsoft HoloLens ${ }^{\circledR}$ and HoloLens $2 \mathbb{}$ were applied.

\subsection{Experiment with the AR Prototype System}

The prototype was tested using the CityGML data accumulated by several Japanese cities. Figure 11 shows the situation where the effect was verified at the actual urban planning site. After the persons in charge of urban planning in several Japanese municipalities utilized this system, it was confirmed that the implementation of AR technology in the form of an interactive content incorporated with the Urban Planning ADE could considerably impact problem solving in the field of urban development.
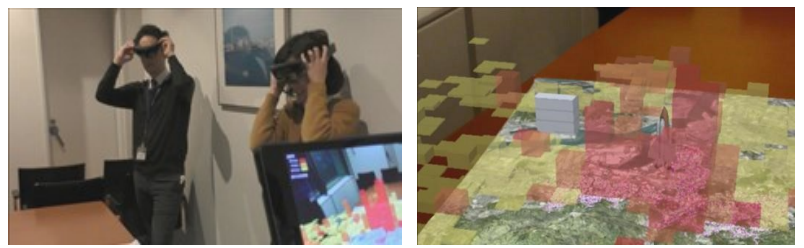

Figure 11. "AR Consensus-Formation System" for i-UR

However, there are certain problems corresponding to the user interface on the operation of AR smart glasses and in reading geospatial data. The first problem can be addressed through additional experiments. The latter problem mainly applies to existing applications such as 3D CAD. Therefore it might be useful to develop plug-in tools or an interface to import CityGML data.

\subsection{Future Prospects}

In terms of technology, progress is expected through future technological innovations such as universally available AR smart glasses which enhance the experience by improving operability. Additionally, if CityGML data is accessible using a wide variety of tools including highly scalable applications such as those utilizing AR technology, it can be concluded that there is room for further expansion of consensus-building approaches among stakeholders, a major issue in urban development.

\section{PROMOTION ACTIVITIES}

This chapter describes promotion activities that municipalities in Japan can take to address the issues described in Chapter 2, and to verify the effectiveness of the i-UR, the data implementation, and the AR tools mentioned above. 


\subsection{Concept of Widespread Deeper Examination}

Figure 12 shows the concept of promotion activities. The ellipse on the upper right represents a motivation to visualize and evaluate the urban structure in detail. Next, data collection methods adapted to the issues need to be developed by every sector. These new data collection and visualization methods will enable planners and stakeholders to examine the issues more closely. These steps form a beneficial cycle, and new insights gained through the cycle increase opportunities for organizing and visualizing data.

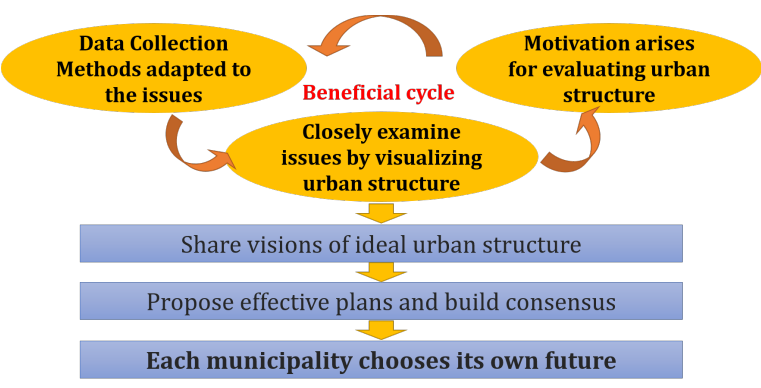

Figure 12. Concept of widespread deeper examination

By promoting a deeper examination of the urban structure, the next steps in urban planning will be executed intrinsically. By examining the visualizations, cultivating motivation for urban planning, and collecting interesting and useful data, a vision of the region's future urban structure can be formulated.

While these visions are important, specific goals and plans to realize these visions are required. Detailed visualization can be a key contributor in finding the best and most efficient way to utilize urban areas. Finally, through the positive cycle and intrinsic actions, each region can choose the best future for their urban structures.

\subsection{Results of Promotion Activities}

According to the concept of this positive cycle, there have been successful examples of adding new elements to urban planning. One of the suggestions was institutionalization of urban structure guidance with respect to transportation.

Setting public transportation axes for guiding dwellings and urban activities is an ultimate means of mobility management. The Fukuoka urban area is the first municipality in Japan to set public transportation axes in legal urban planning. "Public transportation axes" are set to create a livable city where various means of transportation including public transportation are secured. As the public transportation axes are required to have high potential sustainability, not all public transportation can assume this role. Therefore, it is necessary to lay out sustainable and appropriate transportation axes corresponding to urban activities.

Since multiple municipalities are included in the Fukuoka urban area, it is essential to conduct urban planning through consensus-building across municipalities with respect to public transportation, instead of completing individual projects within municipalities. To support this consensus-building, we applied the visualization tool for urban structures and set the public transportation axes successfully after conducting case studies for the Fukuoka urban area.
However, the data used for traffic studies cannot be handled by the Urban Planning ADE at present, so it is necessary to process this data separately. It is desirable to create new ideas and systems, and by extending the standard accordingly, it is possible to have a clearer awareness of data-driven urban development. As the Urban Planning ADE is an open standard and its improvement can be examined by the public, the authors of this paper have begun the development of updated version of the Urban Planning ADE including the new elements described above. In addition, since CityGML 3.0 is going to make a significant expansion of transportation module, making adjustments should be considered in anticipation of that.

\subsection{CityGML-Urban Planning ADE Ideathon}

For further advanced urban planning, the Cabinet Office of Japan, the Ministry of Land, Infrastructure, Transport and Tourism of Japan, and the Urban Structure Visualization Promotion Organization in collaboration with the OGC held the CityGML-Urban Planning ADE Ideathon in Japan. Focused on local Japanese municipalities using CityGML, the events took place on October 3-4, 2019, in Chino City, Nagano Prefecture, and February 12-14, 2020, in Tokyo. The events included participants from government, academic, and private sectors (iUrban Exchange Meeting Conference 2020, 2020).

In the Ideathon, participants were expected to share knowledge, discuss the expansion of applications of CityGML and the Urban Planning ADE in Japan, and the demand for updated versions in the future. At the first meeting, participants discussed the use and dissemination of CityGML in Japan, utilization strategies for the Urban Planning $\mathrm{ADE}$, and directions in which they wish to proceed for future versions. At the second meeting, more than 310 local government staff in total reported and discussed on their experiences in applying CityGML and the Urban Planning ADE for specific planning situations as shown in Figure 13 (i-Urban Exchange Meeting Conference 2020 Secretariat, Simmons, 2020). Various ideas were created through the discussions with OGC members and reflected in the Urban Planning ADE. It is expected that discussions will continue on various occasions including OGC as well as international expert groups on urban planning.
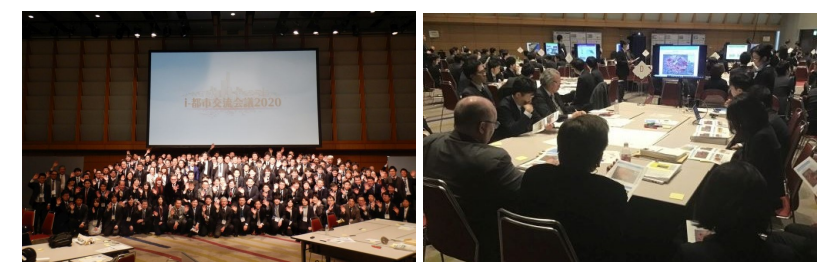

Figure 13. i-Urban Exchange Meeting Conference 2020

\section{CONCLUSIONS AND FUTURE WORK}

This paper presented the conceptual modeling and development of the CityGML Urban Planning ADE, its implementation and possible applications, visualization experiments, as well as promotion activities corresponding to the i-Urban Revitalization data in municipalities in Japan. The results indicate the effectiveness of utilizing CityGML and the Urban Planning ADE, confirmed the validity of the ADE architecture for "Mieruka (visualization)", and constructed various tools centered around CityGML to expand the use of i-Urban Revitalization for diverse applications in municipalities, such as comparative analyses of cities, formulating master plans, and consensus-building using AR technologies. 
Further work should consider an extension of the Urban Planning ADE to reflect additional needs of users, such as advanced statistical data handling, simplification of the ADE structure and flexible mechanisms to apply the ADE, and integration with other useful data (e.g. transportation networks). In addition, promotion activities should be accelerated to increase the number of users and software tools of the Urban Planning ADE. The i-Urban Revitalization and related technologies can contribute to prompt and efficient urban revitalization through the utilization of open standards.

\section{ACKNOWLEDGEMENTS}

The authors would like to thank Prof. Volker Coors from HFT Stuttgart, Mr. Carsten Rönsdorf from Ordnance Survey, Dr. Claus Nagel and Dr. Lutz Ross from virtualcitySYSTEMS $\mathrm{GmbH}$, Mr. Karl-Heinz Häfele, Dr. Joachim Benner, and Mr. Andreas Geiger from Karlsruhe Institute of Technology, OGC CityGML Standards WG members, Mr. Tadaharu Uchida, Mr. Yuya Miyasaka, Mr. Toshinori Maruya, and officers from over 200 municipalities in Japan for rich discussions and valuable comments. All the base map in figures 3 , 4, and 10 contains the GSI Tiles provided by the Geospatial Information Authority of Japan (https://maps.gsi.go.jp/development/ichiran.html).

\section{REFERENCES}

Airaksinen, E., Bergström, M., Heinonen, H., Kaisla, K., Lahti,K., Suomisto, J., 2019. The Kalasatama digital twins project-The final report of the KIRA-digi pilot project. Technical report, City of Helsinki. www.hel.fi/static/liitteet2019/Kaupunginkanslia/Helsinki3D_Kalasatama_Digital_Twin s.pdf (18 April 2020).

Akahoshi, K., Ishii, N., Kishii, T., 2010. Study on Propulsive Movement of Visualization of Urban Structure of Kanto Region -Case Study on the Commission for the Future of Urban Structure of Kanto Region-. The annual conference of the City Planning Institute of Japan, No.45-3, pp.169-174. (In Japanese)

Akahoshi, K., Miyazaki, K., Tagawa, E., Fukushima, T., Ishii, N., 2018. Study on Urban Planning through a Visualization of Urban Structure of Fukuoka Prefecture. Reports of the City Planning Institute of Japan. (In Japanese)

Biljecki, F., 2017. Level of detail in 3D city models. PhD thesis, Delft University of Technology, Delft, the Netherlands.

Biljecki, F., Kumar, K., Nagel, C., 2018. CityGML Application Domain Extension (ADE): overview of developments. Open Geospatial Data, Software and Standards, 3(13).

Burggraf, D., 2015. OGC KML 2.3. Open Geospatial Consortium, OGC 12-007r2. www.ogc.org/standards/kml

Cabinet Decision, 2018. Basic Policy on Economic and Fiscal Management and Reform 2018. www5.cao.go.jp/keizai-shimon/ kaigi/cabinet/2018/2018_basicpolicies_en.pdf(18 April 2020).

Cabinet Office of Japan, 2019. Data Encoding Specification of i-Urban Revitalization -Urban Planning ADE-, version 1.1. www.kantei.go.jp/jp/singi/tiiki/toshisaisei/itoshisaisei/iur/ (18 April 2020).

Fukuoka Prefecture, the Building Research Institute Japan, the Urban Structure Evaluation Special Committee of the City Planning Institute of Japan, 2019. The main features of the urban structure visualization. minna.mieruka.city/main-features (18 April 2020).

Gröger, G., Kolbe, T. H., Nagel, C., Häfele, K.-H., 2012. OGC City Geography Markup Language (CityGML) Encoding Standard. Open Geospatial Consortium, OGC 12-019. www.opengis.net/spec/citygml/2.0

i-Urban Exchange Conference 2020, 2020. meet2020.kashika.or.jp (18 April 2020).

i-Urban Exchange Conference 2020 Secretariat, Simmons, S., 2020. Addressing Urban Revitalization challenges in Japan with OGC standards. OGC Blogs. www.ogc.org/blog/3172 (18 April 2020).

Jamei, E., Mortimer, M., Seyedmahmoudian, M., Horan, B., Stojcevski, A., 2017. Investigating the Role of Virtual Reality in Planning for Sustainable Smart Cities. Sustainability, 9(11), 2006.

Kutzner, T., Hijazi, I., Kolbe, T. H., 2018. Semantic Modelling of 3D Multi-utility Networks for Urban Analyses and Simulations - The CityGML Utility Network ADE. Int. J. 3-D Inf. Model. (IJ3DIM), 7 (2), 1-34.

Kutzner, T., Chaturvedi, K., Kolbe, T. H., 2020. CityGML 3.0: New Functions Open Up New Applications. PFG - Journal of Photogrammetry, Remote Sensing and Geoinformation Science, $88,43-61$.

Nouvel, R., Kaden, R., Bahu, J.-M., Kaempf, J., Cipriano, P., Lauster, M., Benner, J., Munoz, E., Tournaire, O., Casper, E., 2015. Genesis of the CityGML Energy ADE. Proc. of Int. Conf. CISBAT 2015 on Future Buildings and Districts Sustainability from Nano to Urban Scale, LESO-PB, EPFL, 931-936.

Oswalt, P. (Ed), 2005. Shrinking Cities. Volume 1: International Research. Hatje Cantz, Ostfildern-Ruit.

Ramos, F., Trilles, S., Torres-Sospedra, J., Perales, F. J., 2018. New Trends in Using Augmented Reality Apps for Smart City Contexts. ISPRS Int. J. Geo-Inf., 7(12), 478.

Regulation for Enforcement of the City Planning Act. Construct ion Ministry Ordinance No. 49 of 1969, Japan, 2018. elaws.e-go v.go.jp/search/elawsSearch/elaws_search/lsg0500/detail?lawId= 344M50004000049 (18 April 2020) (in Japanese).

Social Capital Development Council, 2007. Report on Urban Transportation and Urban Development Subcommittee. www.mlit.go.jp/singikai/infra/city_history/city_planning/10/ima ges/01.pdf (18 April 2020) (In Japanese)

Soon, K. H., Khoo, V. H. S., 2017. CityGML Modelling for Singapore 3D National Mapping. Int. Arch. Photogramm. Remote Sens. Spatial Inf. Sci., XLII-4/W7, 37-42.

Statistics Bureau of Japan, 1996. Method of Demarcation for Grid Square. www.stat.go.jp/english/data/mesh/05.html (18 April 2020)

Van den Brink, L., Stoter, J., Zlatanova, S., 2013. Establishing a national standard for 3D topographic data compliant to CityGML. Int. J. Geogr. Inf. Sci., 27(1), 92-113. 